\title{
Frequency distribution of mouth breathing in children based on age and gender
}

\author{
Yoswita Damayanti*, Williyanti Soewondo*, Risti Saptarini Primarti* \\ *Department of Pedodontics, Faculty Of Dentistry Universitas Padjadjaran
}

\begin{abstract}
Introduction: Mouth breathing is one of the bad habits caused by respiratory tract obstruction, a habit, or the anatomically incompetent lip shape. It causes an abnormality on the customs of dentofacial, academic, health, and children behavior. The purpose of this research is to find out the percentage of children aged 6-12 years old who have a mouth breathing habit in Pedodontics Installation of Dentistry Unpad Bandung, in September-October 2011. Methods: The study was performed using descriptive method. The study subject are 110 children collected by accidental sampling. Research conducted by clinical examination of extra and intra oral as well as a questionnaire through interviews. Results: The results showed that there were 12 children who have a mouth breathing $(10.1 \%)$, on the basis of age there are 3 children (25\%) at the age of 10 years at most have a habit of breathing through the mouth, and on the basis of gender, there are five male children $(41.7 \%)$ and 7 female children who have a habit of breathing through the mouth $(58,3 \%)$. Conclusion: Conclusions of this research showed that the frequency distribution of a child with mouth breathing in Pedodontics Instalation of RSGM FKG Unpad is relatively low with the number of incidence in female children higher than male children.
\end{abstract}

Keywords: Mouth Breathing, Childern Based on age, Gender

\section{INTRODUCTION}

The bad oral habits in children have long been a dentist's worries. The habit done in the oral cavity is known as oral habit. Oral habit is a recurrent behavior that causes abnormalities in tooth and supporting tissues ${ }^{1,2}$ Oral habit is actually a normal behavior of newborn that are temporary and usually disappear by the age of 3-4 years old. ${ }^{3}$

Oral habit will not cause serious problems to the oral cavity of children aged 0-4 years, because it is a response to the stimulus since the child is in the womb. The response is a sign that the psychological development of the child has begun as seen from spontaneous behaviour or repetitive reaction. ${ }^{4,5,6}$ Oral habit becomes a problem when it is persistent, that is still done when the child enters school age or when the permanent tooth is erupted. These habits can cause localized damage such as malocclusion. ${ }^{3}$

According to Moyers, normal oral habit plays a role in assisting the formation of dentofacial function as well as the normal development of the face and physiologic occlusion. Conversely, abnormal oral habit results in disturbance to the development of dentofacial structures. These bad oral habit that often occurs in a child may be breathing through the mouth, bruxism, lip sucking 
and biting, abnormal speech habits and tendency to bite hard objects. ${ }^{7}$ One of the bad oral habits that is discussed here is mouth breathing. Breathing is one of the vital functions in human body. Normal breathing is the respiration process that occurs through the nose, but can be turned into respiration through the mouth as compensation to the condition or habits obtained after birth. ${ }^{8}$ Such habits may occur in response to respiratory tract damage resulting in children breathing through the mouth depending on the size, duration, and length that this habit occurs. ${ }^{9}$ Patients generally have a mixed respiratory patterns that are partly through mouth and partly through nose, cases of breathing completely through the mouth are rare. ${ }^{10}$

Abreu discovered that $55 \%$ from 370 children in Brazil have the habits of breathing through their mouth. ${ }^{11}$ Menezes studied that the prevalence of mouth breathing in children aged 8-10 years old in Santo Amaro is $53 \%$ from 150 children taken as sample. ${ }^{10}$ Felcar found out that the prevalence of mouth breathing in school kid in primary school covered as big as $56.8 \%$ from 496 samples taken. Another research done, in Cibiru Bandung Campus of Primary School of Sample Lab of Indonesia University of Education (Universitas Pendidikan Indonesia) on children aged between 6-12 years old showed that $16.14 \%$ of the children have mouth breathing habits. ${ }^{12}$

Based on the above data, we can conclude that the prevalence of mouth breathing in children is very high. Children with a habit of breathing through the mouth that lasts for a long time especially during the critical period of facial growth not only causes permanent facial deformities and abnormal bites (malocclusion), but also affects the functional, structural, pathological, postural, and child behaviour. ${ }^{10}$

Some of these changes include a long face known as adenoid facies, unenclosed incompetence, dry lips, hypotonus cheek muscles, high palatal arch, jaw-arch narrowing, and occlusal relation with a class II or III skeletal profile. ${ }^{10,13}$

The adverse impact of breathing through the mouth has been widely proved by existing research. Bresollin finds children breathing through the mouth because allergic rhinitis has a long face with a narrow and retrognatic maxilla.
Souki finds a high prevalence of malocclusion in children breathing through the mouth. Negative effects of children breathing through the mouth not only affect the development of the jaw and the formation of cranium and occlusion developments, but also the general health of the children, their academic, and behavior. ${ }^{14,13}$

Most of the health professionals and parents are unaware of the negative effects of mouth breathing habits on the normal growth of the face and the physical health of the child. This causes the problem to be often ignored and considered unimportant. ${ }^{13}$ The role of the healthcare community (including general dentists as well as pedodontics specialist) is essential for diagnosing child patients who have a habit of breathing through the mouth by looking at their clinical signs. Symptoms of breathing through the mouth that are known and treated early, can prevent adverse effects on the development of dentofacial structures and also the medical and social problems.

Child dentistry installation at the Dental Hospital of the Faculty of Dentistry of Padjadjaran University (RSGM Unpad) Bandung provides services that include prevention, diagnosis, and dental care for children. Research on the frequency of mouth breathing in the child dentistry installation has never been done.

Based on the above background, the author is interested to know the percentage of mouth breathing habits in children aged 6-12 years in the child dentistry installation of Dental Hospital of University Padjadjaran (RSGM Unpad). The purpose of research is to obtain data on the distribution of the frequency of the habit of breathing through the mouth in children aged 6-12 years who come to the child dentistry installation of Dental Hospital of University Padjadjaran (RSGM Unpad) Bandung.

\section{METHODS}

The type of research used is descriptive research with the survey technique. Research is conducted through intra oral clinical examination and extra oral on habits of breathing through the mouth and questionnaires through interviews. In this research the data are collected, processed, and presented in the form of a table to obtain the percentage of children who have a habit of breathing through the 
mouth according to age and gender that comes to the child dentistry installation of Dental Hospital of University Padjadjaran (RSGM Unpad) Bandung. The research population is all children aged 6-12 years old who came to the dental installation of Dental Hospital of University Padjadjaran (RSGM Unpad) Bandung during the period when the study took place (September-October).

Sample collection is done by accidental sampling technique with these population criteria: aged 6-12 years, healthy physically, parents or guardians willing to fill informed consent and cooperative.

\section{RESULTS}

Research on the percentage of mouth breathing in children is done in the child dentistry installation of Dental Hospital of Padjadjaran University (RSGM Unpad) Bandung. Research was conducted in September-October 2011. The number of samples obtained in the research conducted is 110 children consisting of 35 boys and 75 girls. Based on table 1 , it is known that the number of children examined at the 6-year-old child dentistry

\begin{tabular}{ccc}
\multicolumn{3}{c}{ Table 1. Frequency $\begin{array}{c}\text { Distribution of Research Subject } \\
\text { Based on Age }\end{array}$} \\
\hline Age (Years) & N (People) & Percentage (\%) \\
\hline 6 & 18 & 16,36 \\
7 & 19 & 17.3 \\
8 & 20 & 18.2 \\
9 & 20 & 18,2 \\
10 & 17 & 15,5 \\
11 & 8 & 7,3 \\
12 & 8 & 7,3 \\
\hline Total & 110 & 100
\end{tabular}

installation amounted to 18 persons (16.36\%), 7 years of age, 19 (17.3\%), aged 20 (18.2\%), 9 years old (18.2\%), 10 years of age, 17 people (15.5\%), 11 years of age $(7.3 \%)$ and 12 years of age amounted to 8 people $(7,3 \%)$. Table 2 shows that the samples obtained in the child dentistry installation of Dental Hospital of University Padjadjaran (RSGM Unpad) Bandung who had a

Table 2. Frequency Distribution of Research Subject

\begin{tabular}{ccc}
\multicolumn{3}{c}{ Based on Gender } \\
\hline Gender & (People) & Percentage (\%) \\
\hline Boy & 35 & 31,8 \\
Girl & 75 & 68,2 \\
\hline Total & 110 & 100
\end{tabular}

male gender amounted to 35 people (31.8\%), while a sample with a female gender amounted to 75 people $(68.2 \%)$. According to Table 3 it is known that from 110 research subjects there are

Tabel 3. Percentage of Mouth Breathing Habits in Children in the Child Dentistry Installation of RSGM FKG Unpad Bandung.

\begin{tabular}{ccc}
\hline $\begin{array}{c}\text { Incidence of Mouth } \\
\text { Breathing }\end{array}$ & $\begin{array}{c}\mathrm{n} \\
\text { (People) }\end{array}$ & $\begin{array}{c}\text { Percentage } \\
\text { (\%) }\end{array}$ \\
\hline $\begin{array}{c}\text { Breathing Through Mouth } \\
\text { Doesn't Breath Through } \\
\text { Mouth }\end{array}$ & 12 & \\
\hline Total & 98 & \\
\hline
\end{tabular}

12 children $(10.9 \%)$ that has a habit of breathing through the mouth and 98 children (89.1\%) that do not have that habit. Based on table 4 it is known that from 12 children who have habit of breathing by mouth, there are 2 children (16.67\%) at the

Tabel 4. Frequency Distribution and Percentage of Children Aged 6-12 Years Old in RSGM FKG Unpad Bandung That Have Mouth Breathing Habits According to Age.

\begin{tabular}{ccccccc}
\hline \multirow{2}{*}{ Age (Years) } & \multicolumn{2}{c}{ Total } & \multicolumn{2}{c}{ Boy } & \multicolumn{2}{c}{ Girl } \\
\cline { 2 - 7 } & $\mathbf{N}$ (People) & Percentage (\%) & $\mathbf{N}$ (People) & Percentage (\%) & $\mathbf{N}$ (People) & Percentage (\%) \\
\hline 6 & 2 & 16,67 & 1 & 8,3 & 1 & 8,3 \\
7 & 1 & 8,33 & 0 & 0 & 1 & 8,3 \\
8 & 1 & 8,33 & 0 & 0 & 1 & 8,3 \\
9 & 2 & 16,7 & 0 & 0 & 1 & 8,3 \\
11 & 3 & 25,0 & 2 & 16,7 & 0 \\
12 & 2 & 16,7 & 2 & 16,7 & 0 & 8,3 \\
\hline
\end{tabular}


age of 6-year-old consisting of 1 boy (8.3\%) and 1 girl (8.3\%), age 7 and 8 each took place on 1 girl (8.33\%), age 9 , in 2 girls (16.7\%), age 10 in 3 children (25\%) with 2 boys (16.67\%), and 1 girl (8.3\%), 11 years old accounted for 2 boys (16.67\%) While the age of 12 was at 1 girl (8.3\%).

Based on the above data, it is known that most respondents who have a habit of breathing through the mouth are at 10 years of age. According to table 5 , you can know that out of 12 children who have a habit of breathing through

Tabel 5. Frequency Distribution and Percentage of Children Aged 6-12 Years Old in RSGM FKG Unpad Bandung That Have Mouth Breathing Habits According to Gender

\begin{tabular}{ccc}
\hline Gender & N (People) & Percentage (\%) \\
\hline Boy & 5 & 41,7 \\
Girl & 7 & 58,3 \\
\hline Total & 12 & 100 \\
\hline
\end{tabular}

the mouth of 5 children (41.7\%) Male Gender and 8 children (58.3\%) including female gender. Based on table 6, the result of extra oral examination (Lip Seal) on 12 children breathing by mouth, shown

Tabel 6. Clinical Percentage of Extra Oral and Intra Oral Examination of Children Aged 6-12 Years Old Who Have a Habit of Breathing Through the Mouth

\begin{tabular}{cccc}
\hline No & Clinical Symptoms & $\mathbf{n}$ & $\%$ \\
\hline 1 & Lip Seal & 12 & $100,0 \%$ \\
2 & Maxillary Anterior Tooth Protrusion & 10 & $83,3 \%$ \\
3 & High and Narrow Maxillary Arch & 10 & $83,3 \%$ \\
4 & Upper Lips Hypotonus & 10 & $83,3 \%$ \\
5 & Lower Lips Posterior to Maxillary & 5 & $41,7 \%$ \\
6 & Incisors & 11 & $91,7 \%$ \\
7 & Lower Lips Hypertrophy & 5 & $41,7 \%$ \\
\hline
\end{tabular}

as much as 12 people (100\%) have a negative lip seal. Table 6 also describes the percentage of the results of intra oral clinical examinations of children breathing through the mouth. Through that data can be seen that out of 12 children who have a habit of breathing through mouth, as much as 10 people $(83.3 \%)$ have maxillary anterior tooth protrusion.

As much as 12 people (100\%) Or all respondents have a high and narrow maxillary arch. As much as 10 people $(83.3 \%)$ has a hypotonus upper lip, 5 people (41.7\%) Has an open bite (anterior open bite), 11 people $(91.7 \%$ ) has lower lip hypertrophy and 5 people (41.7\%) Have deep bite.

\section{DISCUSSION}

Based on the results of the research on table 3 can be seen that from 110 children aged 6-12 years in the child dentistry installation of Dental Hospital of University Padjadjaran (RSGM Unpad) Bandung, there are 12 children (10.9\%) That has a habit of breathing through the mouth. The figure is quite large compared to the research conducted by Gildasya in 92 children aged 6-12 years at the Foundation of Bina Sejahtera Indonesia (BAHTERA), obtained a prevalence rate of $3.26 \%$ for children who breathe through the mouth. The results of the research are fewer when compared with other research conducted in the Cibiru Bandung Campus of Primary School of Sample Lab of Indonesia University of Education (Universitas Pendidikan Indonesia) amounted to $16.14 \%$ in children aged 6-12 years old. ${ }^{12}$

Other research results abroad showed the prevalence of children who breathe by mouth is $55 \%$ in, while Menezes finds $53 \%$ of the 150 children in Santo Amaro who have a habit of breathing through the mouth. ${ }^{11,10}$ The results from this research correspond to the statement of Cavašani, that the percentage of breathing through the mouth varies from $5 \%-75 \%$.

Research conducted found no significant percentage difference in the habit of breathing through the mouth based on age and gender. The results of this study also got the same result. ${ }^{10,11}$

Information on the habit of breathing through the mouth done by children aged $6-12$ years in the installation of dental dentistry RSGM FKG Unpad Bandung also obtained through the questionnaire by the child accompanied by researchers. Based on the questionnaire (Appendix 8) it is known from 12 children who breathes through the mouth, two children (16.7\%) doesn't realise that they breathes through the mouth, although in the clinical examination of an extra oral or intra oral researcher found signs of the habit. Ten other children (83.33\%) which recognizes having a habit of breathing through the mouth realizing the habit has been done for more than a year. A total of eight children (66.67\%) To admit to doing the habit at all times, one child (8.33\%) does it sometimes, 
and three children (25\%) answered not known. The conclusion of the survey results shows that the habit of breathing through the mouth has long lasted and frequently (at all times). Through interviews conducted by researchers is also known that parents or caregivers do not remind them not to do it.

Stating that the parents do not remind their children not to do the habit because they do not realize the habit of their child and do not know the negative impact that can be inflicted. ${ }^{13}$ Based on the results of the questionnaire on why the child breathes through the mouth, three of the children answered it is hard to breathe if they do not open the mouth, one person answered because it feels comfortable, while eight others cannot explain Why (do not know).

The feeling of comfort caused by breathing through the mouth has make it a habit to the child and if not done, the child will feel uncomfortable. It is in accordance with the literature stating that if the child is told to inspire, the child will take a continuous breath through the mouth, even though they can breath normally through nose with closed lips. ${ }^{14}$

Other questionnaire results showed that 2 children (16.67\%) expressed respiratory disorders such as asthma or nasal congestion, 4 children (33.33\%) stated never, and 6 other children $(50 \%)$ stated that they have no idea. Two children who have been experiencing respiratory distress have admitted that they have suffered from the disease since childhood. The results stated that one of the cause of the child not able to breathe through the nose is due to respiratory disorders or recurrent infections. $^{8}$

The habit of breathing through the mouth can cause malocclusion depending on the moment it start, the duration, intensity, frequency and position where pressure is excerted, and pattern of the patient's growth. ${ }^{15}$ Intensity is how the child does the habit, while the frequency shows how often in one day the habit is done and also how many years the habit is done. ${ }^{3}$ The mechanism of mouth breathing leading to the occurrence of malocclusion is when one does not get enough air when breathing through the nose, the body will automatically program the body to breathe through the mouth to add Air intake by pressing the mandibular downwards and positioning the tongue to the mouth base, consequently the tongue no longer provides support to the arch of the jaw causing the abnormalities of dentofacial development and malocclusion. ${ }^{4}$ The abnormalities of oral cavity due to the habit of breathing through the mouth can be known from the results of an extra oral or intra oral clinical examination. Based on the results of a clinical examination performed in children who breathe through the mouth, abnormalities is present in the dentofacial structure and soft tissues around the mouth (Table 6).

Based on the results, it can be known that all research subjects that have a habit of breathing through the mouth have a negative lip seal. It is in accordance with the statement of Moyers (1998) which stats that children who breathe by mouth have either upper or lower lip that do not meet during the resting state or have a negative lip seal. ${ }^{14}$ Intra oral clinical examination of 12 subjects breathing through mouth, showing 10 people $(83.3 \%)$ has maxillary anterior tooth protrusion, 12 persons (100\%) Or all respondents had a high and narrow maxillary arch, 10 people (83.3\%) has a hypotonus upper lip, 5 people (41.7\%) Has an open bite (anterior open bite), 11 people $(91.7 \%)$ has lower lip hypertrophy and 5 people $(41.7 \%)$ Have deep bite.

The results show that breathing through the mouth is accompanied by abnormalities in the dentofacial structure such as the maxillary anterior tooth protrusion, high and narrow palate, upper lip hypotonus, deep bite and open bite. The results are in accordance with the literature stating that children with habit of breathing through mouth can cause abnormalities in dentofacial structure if untreated. ${ }^{16}$

\section{CONCLUSION}

Based on research that has been done on the children aged 6-12 years in the Child Dentistry installation of Dental Hospital of University Padjadjaran (RSGM Unpad) Bandung, can be concluded that the percentage of mouth breathing habits in children aged 6-12 years in the Child Dentistry installation of Dental Hospital of University Padjadjaran (RSGM Unpad) Bandung is low, with the number of girls who have the habit of breathing through mouth is higher than boys. 


\section{REFERENCES}

1. Boucher CO. Current Clinical Dental Terminology. $2^{\text {nd }}$ Ed. St.Louis: the C.V.Mosby Co. 1974.

2. Finn SB. Clinical Pedodontics.4th Ed. Philadelphia, London and Tokyo: W.B. Saunders Company. 2003. 370-384 pp.

3. Christensen J, Henry W, Fields, Steven M. Adair. Oral Habits. editor: Pediatric Dentistry Infancy Through Adolescent. $4^{\text {th }} \mathrm{Ed}$. Philadelphia: elsevier Saunders. 2005. 436 pp.

4. Barber KT, Luke LSS. Pediatric Dentistry: Postgraduated Dental Handbook Series. Washington : Gardner FA. 1982.

5. Cameron A, Widmer R. Handbook of Pediatric Dentistry. Edinburgh : Mosby. 2003.

6. Koch G, Poulsen S. Pediatric Dentistry - a clinical approach. Copenhagen : Munksgaard. 2001

7. Pinkham JR. Pediatric Dentistry: Infancy through Adolescence. $3^{\text {rd }}$ ed. London : W.B. Saunders Company. 1999. 284-286 pp.

8. Lisiana HS, Hamilah Dk. Implikasi klinis perubahan cara bernafas terhadap aktivitas otot dan struktur dentofasial. MI Kedokteran Gigi. 2004;19(2):89-95.

9. Faria PT, de Oliveira Ruellas AC, Matsumoto MA, Anselmo-Lima WT, Pereira FC. Dentofacial morfology of mouth breathing children. Braz
Dent J. 2002;13(2):129-32. DOI: 10.1590/ s0103-64402002000200010

10. Menezes Valdenice Aparecida De, Leal Rossana Barbosa, Pessoa Rebecca Souza, Pontes Ruty Mara E. Silva. Prevalence and factors related to mouth breathing in school children at the Santo Amaro project-Recife, 2005. Rev. Bras. Otorrinolaringol. 2006;72( 3):394399. DOI: https://doi.org/10.1590/S003472992006000300017.

11. Abreu Rubens Rafael, Rocha Regina Lunardi, Lamounier Joel Alves, Guerra Ângela Francisca Marques. Prevalence of mouth breathing among children. J. Pediatr. 2020;84(5):467470. DOI: https://doi.org/10.1590/S002175572008000600015.

12. Yohana W, Riyanti E. Gambaran Oral Habit pada anak usia 6-12 tahun. Pustaka ilmiah: Unpad. 2007. 4 pp.

13. Jefferson Y. Mouth breathing: adverse effects on facial growth, health, acdemics, and behavior. J of Gen Dentis. 2009;58(1):18-25

14. Moyers RE. Handbook of Orthodontics. 4th ed. Chicago, London, Boca Raton: Year Book Medical Publisher, Chicago, Inc. 1988.156-51 pp.

15. Linder-Aronson S, Woodside DG, Lundström A. Mandibular growth direction following adenoidtectomy. Am J Orthod. 1986 Apr;89(4):273-84. 